\title{
Effect of Cigarette Smoking on Prefrontal Cortical Function in Nondeprived Smokers Performing the Stroop Task
}

\author{
Jiansong Xu', Adrianna Mendrek', Mark S Cohen ',2,3, John Monterosso', Sara Simon', Murray Jarvik', \\ Richard Olmstead', Arthur L Brody', Monique Ernst ${ }^{4}$ and Edythe D London ${ }^{*, 1,3,5}$ \\ 'Department of Psychiatry and Biobehavioral Sciences, David Geffen School of Medicine, University of California Los Angeles, Los Angeles, CA, \\ USA; ${ }^{2}$ Department of Neurology, Radiological Sciences, and Biomedical Physics, David Geffen School of Medicine, University of California Los \\ Angeles, Los Angeles, CA, USA; 'B Brain Research Institute, David Geffen School of Medicine, University of California Los Angeles, Los Angeles, CA, \\ USA; ${ }^{4}$ Mood and Anxiety Disorders Program, National Institute of Mental Health, Bethesda, MD, USA; ${ }^{5}$ Department of Molecular and Medical \\ Pharmacology, David Geffen School of Medicine, University of California Los Angeles, Los Angeles, CA, USA
}

\begin{abstract}
Some reports indicate that cigarette smoking can help smokers focus attention, even when they have not abstained from smoking for a substantial period of time (eg, > I h). Understanding the mechanisms by which smoking affects attention may help in designing smoking cessation treatments. Thirteen nonsmokers and nine smokers participated in two tests of blood oxygen level dependent (BOLD) functional magnetic resonance imaging ( $\mathrm{fMRI}$ ). During $\mathrm{fMRI}$, the participants performed the Stroop Task. There was a 15-min break between the two tests. During the break, each smoker smoked one cigarette. For smokers, the first test began 45-60 min after the last cigarette of ad libitum smoking. The differences in BOLD signal changes between Stroop conditions (ie, incongruent minus congruent) showed a group $\times$ test interaction in the right precentral sulcus, including the putative human frontal eye field (FEF). Smokers, but not nonsmokers, showed greater changes (relative to rest) in BOLD signal in the incongruent than in the congruent condition in the first $\mathrm{fMRI}$ test but not in the second. Even after brief abstinence from smoking, therefore, smokers exhibit compromised functional efficiency in the right FEF and adjacent precentral sulcus in a test of selective attention; and smoking ameliorates this condition.

Neuropsychopharmacology (2007) 32, I42 I - |428. doi: | 0.1038/sj.npp. I 30 I272; published online I 3 December 2006
\end{abstract}

Keywords: $\mathrm{fMRI}$; tobacco; nicotine; attention; brain imaging; prefrontal cortex

\section{INTRODUCTION}

Smokers feel that cigarette smoking helps them concentrate, and that acute abstinence from cigarettes impairs their concentration (Heishman, 1999; Newhouse et al, 2004). The effects of smoking on concentration can be assessed with the Stroop Color-Word Task, which tests the ability to maintain focus in the face of interference (Stroop, 1935). Color-naming words, such as RED, are presented either in congruent (the word matching the color in which it appears) or in incongruent (the word mismatching the color in which it appears) conditions, and participants are instructed to name the color (rather than reading the word) as fast as they can. In the incongruent condition, successful performance of the task involves suppression of interference due to the mismatch of the stimulus word with the color in which it is presented. Most investigators measure

\footnotetext{
* Correspondence: Dr ED London, NPI-Semel Institute for Neuroscience, University of California Los Angeles, 760 Westwood Plaza, C8-528, Los Angeles, CA 90024, USA, Tel: + 310825 0606, Fax: + I 31082508 12, E-mail: elondon@mednet.ucla.edu Received I5 May 2006; revised 3 October 2006; accepted II October 2006
}

the Stroop effect as the difference in reaction time (RT) between incongruent and congruent conditions, and use this measure as an index of interference (MacLeod, 1991).

While enhanced performance on the Stroop Task (ie, reduced Stroop effect) after cigarette smoking has been observed in abstinent smokers ( $>12 \mathrm{~h}$ ) (Mancuso et al, 1999; Pomerleau et al, 1994), it was not clear whether this effect was due to relief from nicotine withdrawal, a facilitating effect of nicotine on selective attention (beyond the preabstinence level), or a combination of both (for review see Heishman et al (1994)). Some studies found that administration of nicotine per se (Provost and Woodward, 1991) or cigarette smoking (Hasenfratz and Battig, 1992; Provost and Woodward, 1991) decreased the Stroop effect in nonsmokers (Provost and Woodward, 1991) or smokers smoking ad libitum (Hasenfratz and Battig, 1992; Provost and Woodward, 1991). These reports suggested that nicotine had an absolute facilitating effect on focusing of attention, but other observations did not support this view. For example, one study found that cigarette smoking decreased the RT for both congruent and incongruent conditions, but did not change the Stroop effect in abstinent smokers (Rusted et al, 2000); and another found that nicotine injection $(0.6 \mathrm{mg}$, i.v. $)$ did not reduce the Stroop 
effect in either nonsmokers or abstinent smokers (Foulds et al, 1996).

Blood oxygen level dependent (BOLD) functional magnetic resonance imaging (fMRI) has been used to investigate the neural systems mediating the effects of nicotine on selective attention of abstinent smokers (Jacobsen et al, 2004) and nonsmokers (Thiel et al, 2005). Abstinent smokers $(>15 \mathrm{~h})$ showed less activity in the left thalamus while they performed an auditory task of selective attention after receiving transdermal nicotine ( 28 or $35 \mathrm{mg}$ ) than after application of a placebo patch (Jacobsen et al, 2004). After chewing nicotine gum ( 1 and $2 \mathrm{mg}$ ), nonsmokers showed improved performance (decreased RT) as well as decreased activity in the prefrontal and parietal cortices while they performed an attention reorienting task (Thiel et al, 2005). Both of these studies of selective attention showed decreases in task-related activity, but in different brain regions (ie, thalamus (Jacobsen et al, 2004) or prefrontal and parietal cortices (Thiel et al, 2005)) after nicotine administration (also see Ernst et al (2001)).

Although these fMRI studies have assessed the effects of nicotine administration on selective attention, comparable tests of the effects of cigarette smoking have not been reported. Notably, smoking provides a manipulation that includes more than the administration of nicotine per se, such as the ritual of smoking and associated conditioned reinforcers (Rose et al, 2003). We therefore, tested nonsmokers and nicotine-dependent smokers with fMRI while they performed the Stroop Color-Word naming task. The objective was to determine the effects of smoking in the absence of substantial withdrawal and cigarette craving so that potential facilitating effects (other than relief of withdrawal) could be observed.

Previous neuroimaging studies found that while performing the Stroop Task, healthy subjects showed higher activity in the presupplementary motor cortex (pre-SMC), anterior cingulate cortex (ACC), and inferior frontal gyrus (IFG) in the incongruent than in the congruent condition (Banich et al, 2000; Bench et al, 1993; Brown et al, 1999; Carter et al, 1995; Gruber et al, 2002; Mead et al, 2002; Milham and Banich, 2005; Pardo et al, 1990b; Taylor et al, 1997). Based on these findings, we predicted that participants in both groups would show higher BOLD signal in these brain regions (ie, pre-SMC, ACC, and IFG) in the incongruent than in the congruent condition. As nicotine administration reduced task-related BOLD signal in participants performing tests of selective attention (Jacobsen et al, 2004; Thiel et al, 2005), we expected smokers to show decreases in task-related BOLD signal change in the pre-SMC, ACC, and IFG after smoking. These brain areas have been implicated in mediating response preparation, distracter inhibition, and conflict monitoring during the Stroop Task (Banich et al, 2000; Bench et al, 1993; Brown et al, 1999; Carter et al, 1995; Gruber et al, 2002; Mead et al, 2002; Milham and Banich, 2005; Pardo et al, 1990a; Taylor et al, 1997).

\section{MATERIALS AND METHODS}

\section{Experimental Subjects}

We recruited potential research participants through flyers and newspaper advertisements. Those who passed an initial telephone screening were invited for further assessment after providing written informed consent, as approved by the Institutional Review Board of the University of California Los Angeles. The participants completed questionnaires related to cigarette smoking psychiatric diagnosis (including the Fagerström Test for Nicotine Dependence as a measure of nicotine dependence (Heatherton et al, 1991), the Wender Utah Rating Scale (WURS) as an index of childhood attention deficit hyperactivity disorder (ADHD, (Ward et al, 1993), the Beck Depression Inventory (BDI) as an assessment of depressive symptoms (Beck and Beamesderfer, 1974)). Psychiatric disorders were determined using the Structured Clinical Interview for DSM-IV (First et al, 1996) to exclude participants with current psychotic disorders and to determine diagnoses of drug abuse disorders.

We excluded individuals who were younger than 18 or older than 55 years of age, reported a debilitating medical condition, or had a score of $\geqslant 46$ on the WURS. Another exclusion factor was illicit substance abuse, as indicated by self-reports and by results on urine drug screens for cocaine, methamphetamine, opiates, and benzodiazepines at the time of enrollment and at all test sessions. Consumption of $\leqslant 10$ standard drinks of alcohol per week (one standard drink $=12$ ounces of beer, 6 ounces of wine, or a 1.5 ounce shot of 80 -proof hard liquor), as indicated by self-report, was allowed. In addition, marijuana use of $\leqslant 1$ joint per week was allowed, but urine was required to test negative for cannabinoids at each session, and the participants were instructed to refrain from using marijuana for the $72 \mathrm{~h}$ prior to each test session. Right-handedness, as indicated by a self report of using the right hand to perform at least six out of seven tasks on the Edinburgh Handedness Questionnaire (Oldfield, 1971), and a selfreport of smoking at least 10 cigarettes a day for the 2 years prior to enrollment were inclusion requirements.

Thirteen nonsmokers (smoked $\leqslant 5$ cigarettes life time) and nine smokers were studied with fMRI. Seven of the nonsmokers were men, $18-53$ years of age $($ mean $=34.9$, $\mathrm{SD}=10.4)$. Their BDI scores ranged from 0 to 10 (mean $=$ $4.2, \mathrm{SD}=3.1$ ), and WURS ranged from 1 to 27 (mean $=11.8$, $\mathrm{SD}=9.1$ ). The number of days they used alcohol ranged 0 to 5 within the last 30 days (mean $=1.7, \mathrm{SD}=1.9$ ). Five of the smokers were men, $22-50$ years of age $($ mean $=37.5$, $\mathrm{SD}=8.8)$. Their $\mathrm{BDI}$ scores ranged from 0 to $9($ mean $=2.4$, $\mathrm{SD}=3.2$ ), and their WURS ranged from 4 to 39 (mean = 12.4, $\mathrm{SD}=4.4)$. The number of days they used alcohol ranged 0 to 10 within the last 30 days (mean $=2.6$, $\mathrm{SD}=3.6)$. None of the participants in either group reported using marijuana within the 30 days preceding the study. The groups did not differ significantly in age, BDI score, WURS, and alcohol use. The smokers reported smoking 13-28 cigarettes per day $($ mean $=20, \mathrm{SD}=4.2)$ and had smoked regularly for 5-30 years (mean $=17, \mathrm{SD}=8.9$ ). Their scores on the Fagerström Test for Nicotine Dependence, a 10-point scale (Heatherton et al, 1991), ranged from 3 to $8($ mean $=4.9, \mathrm{SD}=1.5)$.

\section{Experimental Design}

Each subject was scanned in two tests, separated by a 15 -min break. Testing began between 1400 and $1600 \mathrm{~h}$, 
when normal daily smoking behavior produces a relatively stable plateau of nicotine in blood (Benowitz et al, 1983). Smokers were allowed to smoke ad libitum up to 45-60 min before the first test. After acquisition of the first set of fMRI data, each participant was removed from the scanner for 15 min. During this time, nonsmokers went outdoors and relaxed, and smokers did the same but also each smoked a cigarette of their usual brand. Then all subjects were re-positioned in the scanner for acquisition of the second test. For smokers, the time between cigarette smoking during the break and the beginning of the second test was $<20 \mathrm{~min}$.

Before acquisition of each set of fMRI data, smokers were evaluated for cigarette withdrawal using the 25-item Shiffman/Jarvik Withdrawal Scale (SJWS) (Jarvik et al, 2000; Schuh and Stitzer, 1995). Cigarette craving was also assessed using the Urge to Smoke (UTS) scale (Jarvik et al, 2000) before each test. The score of each subscale of either SJWS or UTS ranges from ' 1 ' to ' 7 ', with score ' 1 ', ' 4 ', and ' 7 ' corresponding to 'definitely no withdrawal or craving symptom', 'possibly withdrawal or craving symptom', and 'definitely withdrawal or craving symptom', respectively. The concentration of $\mathrm{CO}$ in expired air was also measured (parts per million (ppm)).

\section{Task Design}

This study used a block design with congruent, incongruent, and rest conditions. Three words, RED, BLUE, and GREEN were displayed in color as the congruent (matching) and incongruent (mismatched) stimuli. During rest, a cross was displayed at the center of the screen, and subjects fixed their eyes on this cross without responding. All events were programmed into two scripts with different sequences of congruent and incongruent blocks. Each script consisted of four congruent, four incongruent, and nine rest blocks. There were seven trials in each task block, and each stimulus was presented for $1 \mathrm{~s}$ with an inter-stimulus interval of $2 \mathrm{~s}$. Thus, each task block lasted $21 \mathrm{~s}$. All rest blocks lasted $17 \mathrm{~s}$, except for the first one, which lasted $19 \mathrm{~s}$. Before each task block, the instruction, 'Identify the Color' was presented; and before each rest block, the instruction was 'Rest'. All instructions were presented for $2 \mathrm{~s}$. Each entire script lasted $367 \mathrm{~s}$. Each participant was instructed to respond to the displayed color as fast as possible by pressing a button with his or her right hand. Button presses by the index, middle, and ring finger corresponded to red, blue, and green, respectively.

\section{Scanning Parameters}

Functional images were acquired on a 3 T MRI scanner (GE, Signa with the EPI upgrade from Advanced NMR Systems), using $\mathrm{T}^{*}$ weighted gradient-recalled EPI, with blood oxygen level-dependent (BOLD) contrast $(\mathrm{TR}=3000 \mathrm{~ms}$, $\mathrm{TE}=42 \mathrm{~ms}$, flip angle $=80^{\circ}$, slice thickness $=4 \mathrm{~mm}$ with a $1 \mathrm{~mm}$ inter-slice interval, matrix of $64 \times 64$, in-plane resolution $=3.12 \mathrm{~mm}^{2}$ ). One hundred nineteen images were acquired for each of 16 axial slices through the brain. Sixteen slices cover the majority of the brain except the most dorsal portion of the frontoparietal cortex and the most ventral portion of frontal and temporal cortices.
High-resolution, T2-weighted, EPI, anatomical images of the whole brain (23-25 slices, 4 -mm thick) were acquired in each scanning session to help define the locations of the BOLD signals.

\section{Statistical Analysis}

Behavioral data. Two repeated measures Analyses of Variance (ANOVAs) were conducted, with one modeling reaction time and the other modeling accuracy. For both analyses, task condition (congruent $v s$ incongruent) and tests (first $v s$ second) were within-subject variables and group (smoker $v s$ nonsmoker) was a between-subject variable. As tests were confounded with the smoking manipulation, we looked to the interaction between tests and study groups (smoker vs nonsmoker) for evidence of an effect of smoking, apart from any effects of order. The Pearson correlations between the scores of Fagerström Test and Stroop effect exhibited by smokers in the two tests were also assessed.

Imaging data. We used Statistical Parametric Mapping (SPM2, Welcome Department of Cognitive Neurology, London) for motion correction, spatial normalization, smoothing, and statistical analysis. For each subject, the functional scans were aligned to the first functional image and corrected for motion, co-registered, spatially normalized to the EPI template from SPM2, then smoothed with a 12-mm FWHM Gaussian filter. Then, the functional data were filtered with a 128-s high pass temporal filter. We constructed model time courses for each event block, that is, congruent, incongruent, rest, and instruction, by convolving a boxcar waveform representing the times of the presentation of each block with the canonical hemodynamic response function of SPM2. We then analyzed the data in comparison with these model time courses in the context of the general linear model.

Our statistical tests involved two levels, first at the single subject level (fixed effect model), and then at the group level (random effects model). First, SPM(T) maps of desired contrasts (eg, incongruent minus rest, congruent minus rest, incongruent minus congruent), for the imaging data from first and second test, and the combined data from both tests were generated for each subject. In addition, comparisons between tests were made for the aforementioned contrasts between conditions for each subject. Then these contrasts were entered into a second level analysis. One sample $t$-tests were used to assess the group mean BOLD signal changes related to the congruent (congruent minus rest) or the incongruent (incongruent minus rest) condition, or the group mean of the difference in BOLD signal change between the two conditions (incongruent minus congruent) of nonsmokers and smokers, respectively, in the first and second tests, and the combined data from both tests. One sample $t$-tests were also used to identify regions where there were differences between the first and second tests in contrast of incongruent minus congruent condition of nonsmokers and smokers, separately. Two sample $t$-tests were used to make group comparisons (smokers $v s$ nonsmokers) in BOLD signal changes between conditions (incongruent minus congruent). Two sample $t$-tests were also used to make between-group 
(nonsmokers vs smokers) comparisons of differences in BOLD signal changes between tests related to the contrast of incongruent minus congruent condition. A voxel-level height threshold of $p<0.001$ (uncorrected), and a cluster level extent threshold of $p<0.05$, corrected for multiple comparisons, were used to identify significant task-related activity in a whole brain analyses. To quantify the magnitudes of BOLD signal changes within significant clusters, these clusters were functionally defined as regions of interest (ROIs), and the mean signal change in each ROI was extracted with the SPM2-compatible ROI analysis tool Marsbar (Brett et al, 2002). The Pearson correlations between the scores of Fagerström Test for Nicotine Dependence and the differences of percent changes of BOLD signal between incongruent and congruent conditions of each ROI of smokers in the two tests were assessed with SPSS.

\section{RESULTS}

\section{Subjective Withdrawal and Craving in Smokers}

Before the first test, the self reported mean scores on the SJWS subscales ranged from 1.2 to 4.8 , and the mean UTS score was 4.16 (Table 1). These scores indicated that smokers did not experience severe withdrawal or craving symptoms before the first test (see Materials and methods for the definition of scores). Self-reports of withdrawal and craving before the first and second fMRI tests did not show significant differences (Table 1), in keeping with the fact that abstinence from smoking was brief in both cases: $45-60 \mathrm{~min}$ for the first test and $<20 \mathrm{~min}$ for the second. After smoking a cigarette during the break, the average concentration of $\mathrm{CO}$ in expired air showed a small, statistically significant increase (Table 1, $\mathrm{df}=8, t=4.11, p<0.05$ ).

\section{Stroop Task Performance of Nonsmokers and Smokers}

Both groups showed a significant Stroop effect, that is, longer RT during the incongruent than the congruent condition in both first and second tests (paired $t$-test, for

Table I Withdrawal, Craving, and CO in Smokers $(n=9)$

\begin{tabular}{lcc}
\hline & $\begin{array}{c}\text { Prebreak mean } \\
\text { (SD) }\end{array}$ & $\begin{array}{c}\text { Postbreak mean } \\
\text { (SD) }\end{array}$ \\
\hline $\begin{array}{l}\text { Shiffman/janik withdrawal scale } \\
\text { Craving }\end{array}$ & $4.8(1.3)$ & $5.1(1.0)$ \\
Psychological & $2.4(0.8)$ & $2.7(0.6)$ \\
symptoms & & \\
Physical symptoms & $1.2(0.4)$ & $1.4(0.7)$ \\
Sedation & $1.7(0.7)$ & $3.5(2.0)$ \\
Appetite & $4.2(0.6)$ & $4.0(0.3)$ \\
Total score & $14.3(2.3)$ & $16.7(2.8)$ \\
Urge to smoke scale & $4.16(1.8)$ & $3.76(2.2)$ \\
CO (ppm)* & $20.7(9.0)$ & $24.8(8.7)$ \\
\hline
\end{tabular}

* $p<0.05$, significant difference, showing increase in expired $\mathrm{CO}$ after smoking one cigarette.

The highest possible score on the Urge to Smoke Scale and each subscale of Shiffman/Jarvik Withdrawal Scale is ' 7 '. nonsmokers, first test: mean Stroop effect $=115.1 \mathrm{~ms}, \mathrm{SD}=$ 46.3, $t=3.5, p<0.05, \mathrm{df}=12$; second test: mean Stroop effect $=121.6 \mathrm{~ms}, \mathrm{SD}=70.3, t=5.0, p<0.05, \mathrm{df}=12$; for smokers, first test: mean Stroop effect $=138.4 \mathrm{~ms}, \mathrm{SD}=$ 50.2, $t=8.7, p<0.05, \mathrm{df}=8$; second test: mean Stroop effect $=124.1 \mathrm{~ms}, \mathrm{SD}=40, t=8.0, p<0.05, \mathrm{df}=8$ ). There was no significant difference between tests; nor was there a significant group difference in either test. There also were no significant interactions involving the Stroop effect. Scores on the Fagerström Test for Nicotine Dependence were not significantly correlated with the Stroop effect exhibited by the smokers in either test. Neither group showed a significant difference in error rates between the incongruent and congruent condition in either test or between tests.

\section{Task-Related Changes in BOLD Signal}

The imaging data of the two tests of nonsmokers showed no difference and, therefore, were combined. Nonsmokers exhibited significantly higher BOLD signal in the incongruent than in the congruent condition in the left IFG (Figure 1, cluster size $=12609 \mathrm{~mm}^{3}$, MNI coordinates of the peak voxel: $x=-33, y=0, z=21$ ), and in the left pre-SMC (Figure 1, size $=1728 \mathrm{~mm}^{3}$, MNI coordinate of the peak voxel: $x=-9, y=18, z=48$ ). As with the nonsmokers, the combined data from the two tests of smokers also showed significantly higher BOLD signal in the incongruent than in the congruent condition in the left IFG (Figure 2, cluster size $=1971 \mathrm{~mm}^{3}$, MNI coordinates of the peak voxel: $x=$ $-42, y=9, z=21$ ), but also in the left intraparietal sulcus (Figure 2, cluster size $=3942 \mathrm{~mm}^{3}$, MNI coordinates of the peak voxel: $x=-30, y=-75, z=30$ ). Two sample $t$-tests did not show significant difference in task-related changes of BOLD signal in the brain between nonsmokers and smokers in either incongruent or congruent conditions, or in the contrast of incongruent minus congruent condition in either test.

A cluster in the right precentral sulcus, including the putative human frontal eye field (FEF, Figure 3a, cluster

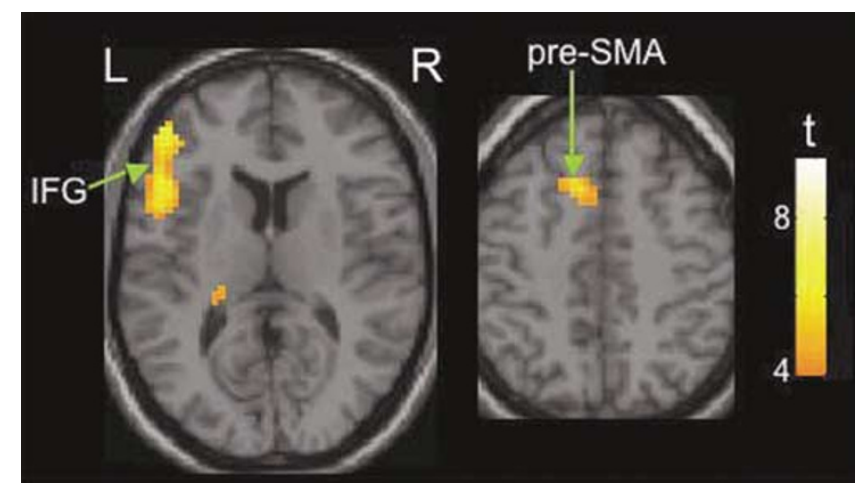

Figure I Nonsmokers $(n=13)$ showed greater increases in BOLD signal from the rest condition in the left inferior frontal gyrus and presupplementary cortex in the incongruent than in the congruent condition. Colors superimposed on the gray scale image, from the single subject TI brain template of SPM2, indicate values of $t$ according to the color bar. Voxel level height threshold $p<0.00$ I, uncorrected. Abbreviations: IFG: inferior frontal gyrus, L: left, pre-SMA: presupplementary motor area, R: right. 


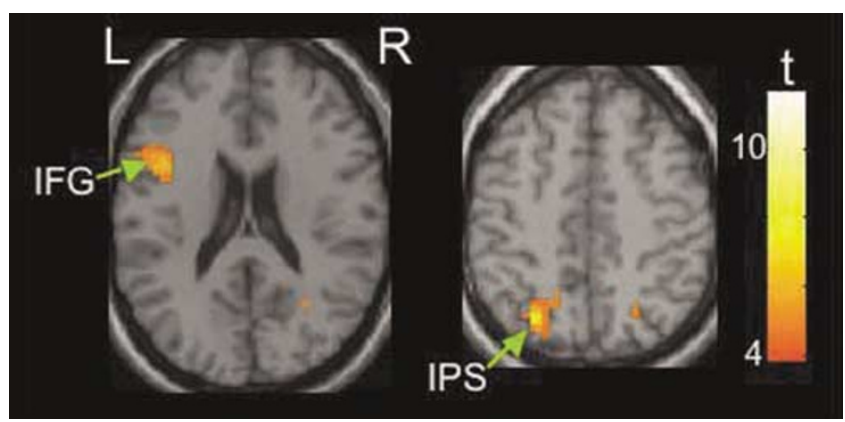

Figure 2 Smokers $(n=9)$ showed greater increases in BOLD signal in the left inferior frontal gyrus and intraparietal sulcus from the rest condition in the incongruent than in the congruent condition. Colors superimposed on the gray scale image, from the single subject TI brain template of SPM2, indicate values of $t$ according to the color bar. Voxel level height threshold $p<0.00$ I, uncorrected. Abbreviations: IFG: inferior frontal gyrus, IPS: intraparietal sulcus, L: left, R: right. a

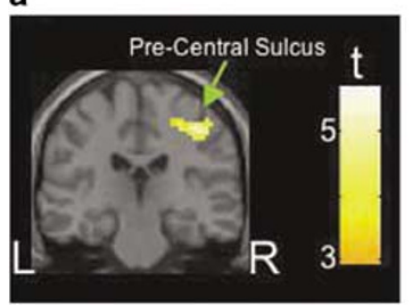

b

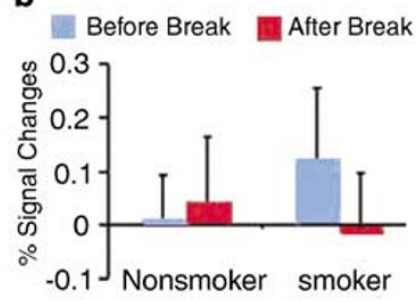

Figure 3 Significant interaction of contrast of incongruent minus congruent condition in the right precentral sulcus, including the putative human frontal eye field (smokers $(n=9)$ vs nonsmokers $(n=13)$ and first vs second test). (a) Colors superimposed on the single subject TI template from SPM2 indicate values of $t$ according to the color bar. (b) Difference in percentage signal change (relative to rest) between the incongruent and congruent conditions. Bar: mean, Error Bar: SD. Voxel level height threshold $p<0.00$ I, uncorrected. Abbreviations: L: left, R: right.

size $=6075 \mathrm{~mm}^{3}$, MNI coordinates of the peak voxel: $x=43$, $y=-22, z=50)$ showed a significant interaction between groups (smokers $v s$ nonsmokers) and tests (first $v s$ second) in the contrast of incongruent minus congruent condition. We defined this cluster as an ROI and assessed changes (relative to rest) in BOLD signal in both the incongruent and the congruent conditions in each test of each subject. ROI analysis indicated that this interaction in the right precentral sulcus reflected greater BOLD signal changes in the incongruent than in the congruent condition of the smokers only in the first test (paired $t$-test, $t=2.5, p<0.05$, $\mathrm{df}=8$ ), but not in the second test (after smoking). Nonsmokers did not exhibit a difference between the two conditions in either test (Figure $3 \mathrm{~b}$ ). There was no significant correlation between nicotine dependence scores (Fagerström Test) and the difference in BOLD signal changes in this ROI between incongruent and congruent conditions of smokers in either test.

\section{DISCUSSION}

When abstinent $<1 \mathrm{~h}$, smokers showed a greater change in BOLD signal in the right precentral sulcus, including the
FEF, in the incongruent than in the congruent condition of the Stroop Task. This difference between the two task conditions was not observed after smokers smoked a cigarette, nor was it exhibited by nonsmokers in either test. Literature regarding selective attention indicates that activity of the FEF (including the adjacent regions around the precentral sulcus) mediates shifts of attention and discrimination between targets and distracters (Astafiev et al, 2003; Hopfinger et al, 2000). For example, FEF neurons in monkeys are activated during discrimination between targets and distracters (Bichot and Schall, 1999; Thompson and Bichot, 2005); and the FEF is activated by distracters while human subjects perform an oddball task (Bledowski et al, 2004). This activation is believed to reflect discrimination of distracters from targets and diversion of attention from distracters (Bledowski et al, 2004). Previous fMRI studies found that activity in the FEF is associated with the diversion of attention in space (Astafiev et al, 2003; Hopfinger et al, 2000), the shifting of attention between objects at the same location, and between features of the same object (Liu et al, 2003; Serences et al, 2004).

Activity of FEF neurons mediates selection, generation, and inhibition of responses after peripheral cues (Astafiev et al, 2003; Connolly et al, 2002; Merriam et al, 2001). The successful performance of the incongruent condition requires inhibition of the interference introduced by the semantic meaning of the word during signal perception, and perhaps also inhibition of the tendency to respond to the semantic meaning during response selection (MacLeod, 1991; Mead et al, 2002). The activity in the FEF observed in the present study may reflect either or both of these types of inhibition. Our study did not, however, distinguish between potential effects of brief abstinence or smoking on these types of inhibition.

Relative to young adults, aged subjects have deficits in inhibition of distracters on a selective attention task (Maylor and Lavie, 1998). They also exhibit larger differences in the activity in the right FEF between the incongruent and congruent conditions than young adults while they perform the Stroop Task during fMRI (Langenecker et al, 2004), suggesting that aging is associated with reduced functional efficiency of the FEF during performance of the Stroop task. The observed interaction in the present study reflects greater activity in the more difficult condition of smokers only and only in the test block before acute smoking. It suggests that the inhibitory function of the right FEF is compromised in smokers abstinent for only $45-60 \mathrm{~min}$; and that this compromise is counteracted by smoking a cigarette.

In the present study, smokers did not report severe withdrawal and craving symptoms immediately before the first test. They also did not show significant differences in withdrawal and craving scores between the first and second tests. Therefore, it is unlikely that the effect of cigarette smoking on the BOLD signal at the right FEF and adjacent precentral sulcus of smokers is due to the relief of subjective nicotine withdrawal or craving for cigarettes. Our findings suggest that chronic smoking, short abstinence (45-60 min) from cigarette smoking, conditions that existed before the initiation of smoking, or any combination of these factors, impaired the functional efficiency of the right FEF of nicotine-dependent smokers on selective attention tasks, 
and that acute smoking a cigarette ameliorated this functional deficit. This acute reversal effect of cigarette smoking on the function of FEF may be one of several factors that help maintain smoking behavior.

In a previous study, smokers, who abstained from cigarette smoking for about $45 \mathrm{~min}$, showed less activation in the parietal cortex and striatum than nonsmokers while they performed a continuous performance task; and that this hypoactivation in smokers was reversed after application of transdermal nicotine $(21 \mathrm{mg},>3 \mathrm{~h}$ ) (Lawrence et al, 2002). In that study and in ours, smokers who were abstinent from cigarette smoking $<60 \mathrm{~min}$, exhibited abnormal brain activation while performing attentional tasks; and this abnormality was reversed by either cigarette smoking or nicotine administration. The two studies, however, show different directions of effects. We found that, before cigarette smoking, smokers showed higher taskrelated activity than nonsmokers (see Figure $3 b$ ) although this difference did not reach our a priori threshold for statistical significance. Notably the two studies used different tasks, and the abnormalities in activation were in different brain regions.

Acetylcholine enhances both bottom-up signal detection and top-down control of signal processing, thereby facilitating the processing of goal-related signals, suppressing the processing of distracters, and increasing the signal/noise ratio in the cortex (for review, see Sarter et al (2005)). Such actions could increase the functional efficiency of cortex, reducing cortical activity (ie, BOLD signal) required for demanding attentional tasks. When delivered through cigarette smoking, nicotine mimics the action of acetylcholine by binding to nicotinic acetylcholine receptors (nAChRs) and promoting acetylcholine release. By this action, cigarette smoking may have reduced BOLD signal at the right FEF and adjacent precentral sulcus in the incongruent condition after cigarette smoking in our study. The same mechanism may explain why nicotine administration decreased task related BOLD signals in the frontal and parietal cortices of nonsmokers performing a selective attention task (Thiel et al, 2005).

It is plausible that reduced functional efficiency in the brain following brief abstinence from smoking ad libitum until the afternoon of testing may reflect desensitization of nAChRs. About $70 \%$ of $\alpha 4 \beta 2 \mathrm{nAChRs}$ in cultured cells are desensitized after brief exposure to $10 \mathrm{nM}(1.6 \mathrm{ng} / \mathrm{ml})$ (Paradiso and Steinbach, 2003). By comparison, smoking one cigarette can elevate arterial plasma nicotine concentrations above $180 \mathrm{nM}(30 \mathrm{ng} / \mathrm{ml})$ for more than $20 \mathrm{~min}$ (Gourlay and Benowitz, 1997). In addition, positron emission tomographic assessment of in vivo nAChR occupancy in smokers indicated that smoking just one cigarette can produce $>88 \%$ occupancy of $\alpha 4 \beta 2 *$ nAChRs for at least $4 \mathrm{~h}$ after smoking (Brody et al, 2006). To the extent that nAChRs in human brain respond to nicotine with desensitization as shown in vitro, smoking ad libitum until 45-60 min before testing could render central nAChRs less responsive to stimulation by endogenous acetylcholine, and thereby decrease functional efficiency. If smokers in this study had a large proportion of their cerebral $\alpha 4 \beta 2^{*}$ nAChRs desensitized at the time of testing, the positive effect of smoking one cigarette on selective attention could reflect activation of a population $\alpha 4 \beta 2^{\star}$ (or other) nAChRs that are resistant to desensitization. Alternatively, the effect may reflect non-nicotine components of tobacco smoke or of the smoking experience.

In the present study, we did not find significant improvement in task performance of smokers after they each smoked a cigarette. At the same time, we observed a decrease in BOLD signal in the incongruent condition of the Stroop task, suggesting improved functional efficiency in the right FEF and adjacent pre-central sulcus. A possible reason for the inconsistency between fMRI and behavioral findings is a greater sensitivity of neuroimaging methods as compared with purely behavioral tests, as observed previously (Bolla et al, 2003, 2004; Eldreth et al, 2004; Goldberg and Weinberger, 2004).

Consistent with our hypothesis and relevant literature (Banich et al, 2000; Brown et al, 1999; Langenecker et al, 2004; Taylor et al, 1997; Zysset et al, 2001), both test groups showed larger increases of BOLD signal from rest in the left IFG during the incongruent than during the congruent condition. Neuroimaging studies have indicated that the left IFG mediates inhibition in verbal working memory (Jonides et al, 1998). Studies using the Stop-signal task found that the right IFG is the main cortical site involved inhibition of motor responses (Aron et al, 2003; Aron and Poldrack, 2006). The findings of different brain regions mediating inhibition in different tasks suggest that the inhibition, or cognitive control, involves multiple brain areas, and the exact location is task dependent.

There are limitations in this study. First, as the sample size is small, the results should be considered as preliminary. In addition, as $\mathrm{CO}$ and nicotine from cigarette smoking may have complex effects on cerebral perfusion (Domino et al, 2004; Ghatan et al, 1998; Rose et al, 2003), they may affect BOLD signal, which is an essential feature of fMRI signal. Nicotine administration, however, did not alter the coupling between the BOLD signal and activity of the visual cortex in response to photic stimulation in a previous study (Jacobsen et al, 2002), suggesting that this potential confound may not contribute to our findings. In our study, significant interaction between subject groups and tests was only observed in the right precentral sulcus and the adjacent FEF, which previous work implicated as contributing to selective attention and response selection. This selective effect is not easily explained by nonspecific effects of $\mathrm{CO}$ and/or nicotine on cerebral perfusion. Lastly, our study does not separate the effects of nicotine from other effects of the smoking experience (physical and emotional). Answering this question would require a larger sample and assay of plasma nicotine.

Our findings suggest that nicotine-dependent smokers have impaired functional efficiency in the right FEF and adjacent precentral sulcus, as evidenced by greater BOLD signal changes when tested in the incongruent than in the congruent condition of the Stroop Task. Nonsmokers did not show this difference between conditions. As smoking a cigarette removed the difference in smokers, it appears that smoking after even brief abstinence can improve functional efficiency. This effect appears to reflect normalization of deficient function rather than a facilitation of brain function beyond the level exhibited by healthy nonsmokers. To the extent that such recovery reflects effects of nicotine per se, 
smokers might achieve this improvement with products that deliver nicotine through routes other than smoking.

\section{ACKNOWLEDGEMENTS}

This work was supported by NIH grants RO1 DA014093 (EDL), RO1 DA015059 (ALB), MOI RR 00865, UC TobaccoRelated Disease Research Program awards 10RT-0091 (EDL) and 11RT-0024 (ALB), VA Merit Review Type I Award (ALB), T32 DA 07272 (JX), and Philip Morris External Research Program and Philip Morris International contract 02066286 (EDL).

\section{REFERENCES}

Aron AR, Fletcher PC, Bullmore ET, Sahakian BJ, Robbins TW (2003). Stop-signal inhibition disrupted by damage to right inferior frontal gyrus in humans. Nat Neurosci 6: 115-116.

Aron AR, Poldrack RA (2006). Cortical and subcortical contributions to stop signal response inhibition: role of the subthalamic nucleus. J Neurosci 26: 2424-2433.

Astafiev SV, Shulman GL, Stanley CM, Snyder AZ, Van E, Corbetta $M$ (2003). Functional organization of human intraparietal and frontal cortex for attending, looking, and pointing. J Neurosci 23: 4689-4699.

Banich MT, Milham MP, Atchley RA, Cohen NJ, Webb A, Wszalek $\mathrm{T}$ et al (2000). Prefrontal regions play a predominant role in imposing an attentional 'set': evidence from fMRI. Brain Res Cogn Brain Res 10: 1-9.

Beck AT, Beamesderfer A (1974). Assessment of depression: The depression inventory. Psychol Measure Psychopharmacol 7: 151-169.

Bench CJ, Frith CD, Grasby PM, Friston KJ, Paulesu E, Frackowiak $\mathrm{R}$ et al (1993). Investigations of the functional anatomy of attention using the Stroop test. Neuropsychologia 31: 907-922.

Benowitz NL, Hall SM, Herning RI, Jacob III P, Jones RT, Osman A-L (1983). Smokers of low-yield cigarettes do not consume less nicotine. N Engl J Med 309: 139-142.

Bichot NP, Schall JD (1999). Effects of similarity and history on neural mechanisms of visual selection. Nat Neurosci 2: 549-554.

Bledowski C, Prvulovic D, Goebel R, Zanella FE, Linden DE (2004). Attentional systems in target and distractor processing: a combined ERP and fMRI study. Neuroimage 22: 530-540.

Bolla K, Ernst M, Kiehl K, Mouratidis M, Eldreth D, Contoreggi C et al (2004). Prefrontal cortical dysfunction in abstinent cocaine abusers. J Neuropsychiatry Clin Neurosci 16: 456-464.

Bolla KI, Eldreth DA, London ED, Kiehl KA, Mouratidis M, Contoreggi $C$ et al (2003). Orbitofrontal cortex dysfunction in abstinent cocaine abusers performing a decision-making task. Neuroimage 19: 1085-1094.

Brett M, Anton JL, Valabregue R, Poline JB (2002). Region of interest analysis using an SPM toolbox. Neuroimage 16: 1140-1141. Ref Type: Abstract.

Brody AL, Mandelkern MA, London ED, Olmstead RE, Farahi J, Scheibal D et al (2006). Cigarette smoking saturates brain $\alpha_{4} \beta_{2}$ nicotinic acetylcholine receptors. Arch Gen Psychiatry 63: 907-915.

Brown GG, Kindermann SS, Siegle GJ, Granholm E, Wong EC, Buxton RB (1999). Brain activation and pupil response during covert performance of the Stroop Color Word task. J Int Neuropsychol Soc 5: 308-319.

Carter CS, Mintun MA, Cohen JD (1995). Interference and facilitation effects during selective attention: $\mathrm{An}_{2}{ }^{15} \mathrm{O}$ PET study of Stroop task performance. Neuroimage 2: 264-272.
Connolly JD, Goodale MA, Menon RS, Munoz DP (2002). Human fMRI evidence for the neural correlates of preparatory set. Nat Neurosci 5: 1345-1352.

Domino EF, Ni L, Xu Y, Koeppe RA, Guthrie S, Zubieta J-K (2004). Regional cerebral blood flow and plasma nicotine after smoking tobacco cigarettes. Prog Neuropsychopharmacol Biol Psychiatry 28: 319-327.

Eldreth DA, Matochik JA, Cadet J-L, Bolla KI (2004). Abnormal brain activity in prefrontal brain regions in abstinent marijuana users. Neuroimage 23: 914-920.

Ernst M, Heishman SJ, Spurgeon L, London ED (2001). Smoking history and nicotine effects on cognitive performance. Neuropsychopharmacology 25: 313-319.

First MB, Spitzer RL, Gibbon M, Williams J (1996). Structured Clinical Interview for DSM-IV Axis I Disorders-Patient Edition (SCID-I/P, Version 2.0). Biometrics Research Department, New York State Psychiatric Institute: New York.

Foulds J, Stapleton J, Swettenham J, Bell N, McSorley K, Russell MAH (1996). Cognitive performance effects of subcutaneous nicotine in smokers and never-smokers. Psychopharmacology (Berlin) 127: 31-38.

Ghatan PH, Ingvar M, Eriksson L, Stone-Elander S, Serrander M, Ekberg $\mathrm{K}$ et al (1998). Cerebral effects of nicotine during cognition in smokers and non-smokers. Psychopharmacology (Berlin) 136: 179-189.

Goldberg TE, Weinberger DR (2004). Genes and the parsing of cognitive processes. Trends Cogn Sci 8: 325-335.

Gourlay SG, Benowitz NL (1997). Arteriovenous differences in plasma concentration of nicotine and catecholamines and related cardiovascular effects after smoking, nicotine nasal spray, and intravenous nicotine. Clin Pharmacol Ther 62: 453-463.

Gruber SA, Rogowska J, Holcomb P, Soraci S, Yurgelun-Todd D (2002). Stroop performance in normal control subjects: an fMRI study. Neuroimage 16: 349-360.

Hasenfratz M, Battig K (1992). Action profiles of smoking and caffeine: Stroop effect, EEG, and peripheral physiology. Pharmacol Biochem Behav 42: 155-161.

Heatherton TF, Kozlowski LT, Frecker RC, Fägerström KO (1991). The Fägerström Test for Nicotine Dependence: a revision of the Fägerström Tolerance Questionnaire. Br J Addict 86: 1119-1127.

Heishman SJ (1999). Behavioral and cognitive effects of smoking: relationship to nicotine addiction. Nicotine Tob Res 1(Suppl 2): S143-S147.

Heishman SJ, Taylor RC, Henningfield JE (1994). Nicotine and smoking: a review of effects on human performance. Exp Clin Psychopharmacol 2: 345-395.

Hopfinger JB, Buonocore MH, Mangun GR (2000). The neural mechanisms of top-down attentional control. Nat Neurosci 3: 284-291.

Jacobsen LK, Cyril D’Souza D, Einar Mencl W, Pugh KR, Skudlarski P, Krystal JH (2004). Nicotine effects on brain function and functional connectivity in schizophrenia. Biol Psychiatry 55: 850-858.

Jacobsen LK, Gore JC, Skudlarski P, Lacadie CM, Jatlow P, Krystal $\mathrm{JH}$ (2002). Impact of intravenous nicotine on BOLD signal response to photic stimulation. Magn Reson Imag 20: 141-145.

Jarvik M, Madsen D, Olmstead R, Iwamoto-Schaap P, Elins J, Eisenberger $\mathrm{N}$ et al (2000). Blood nicotine levels and subjective craving for cigarettes. Pharmacol Biochem Behav 66: 553-558.

Jonides J, Smith EE, Marshuetz C, Koeppe RA, Reuter-Lorenz PA (1998). Inhibition in verbal working memory revealed by brain activation. Proc Natl Acad Sci USA 95: 8410-8413.

Langenecker SA, Nielson KA, Rao SM (2004). fMRI of healthy older adults during Stroop interference. Neuroimage 21: 192-200.

Lawrence NS, Ross TJ, Stein EA (2002). Cognitive mechanisms of nicotine on visual attention. Neuron 36: 539-548. 
Liu T, Slotnick SD, Serences JT, Yantis S (2003). Cortical mechanisms of feature-based attentional control. Cereb Cortex 13: 1334-1343.

MacLeod CM (1991). Half a century of research on the Stroop effect: an integrative review. Psychol Bull 109: 163-203.

Mancuso G, Warburton DM, Melen M, Sherwood N, Tirelli E (1999). Selective effects of nicotine on attentional processes. Psychopharmacology (Berlin) 146: 199-204.

Maylor EA, Lavie N (1998). The influence of perceptual load on age differences in selective attention. Psychol Aging 13: 563-573.

Mead LA, Mayer AR, Bobholz JA, Woodley SJ, Cunningham JM, Hammeke TA et al (2002). Neural basis of the Stroop interference task: response competition or selective attention? J Int Neuropsychol Soc 8: 735-742.

Merriam EP, Colby CL, Thulborn KR, Luna B, Olson CR, Sweeney JA (2001). Stimulus-response incompatibility activates cortex proximate to three eye fields. Neuroimage 13: 794-800.

Milham MP, Banich MT (2005). Anterior cingulate cortex: an fMRI analysis of conflict specificity and functional differentiation. Hum Brain Mapp 25: 328-335.

Newhouse PA, Potter A, Singh A (2004). Effects of nicotinic stimulation on cognitive perfomance. Curr Opin Pharmacol 4: 36-46.

Oldfield RC (1971). The assessment and analysis of handedness: the Edinburgh inventory. Neuropsychologia 9: 97-113.

Paradiso KG, Steinbach JH (2003). Nicotine is highly effective at producing desensitization of rat alpha4beta2 neuronal nicotinic receptors. J Physiol 553: 857-871.

Pardo JV, Pardo PJ, Janer KW, Raichle ME (1990a). The anterior cingulate cortex mediates processing selection in the Stroop attentional conflict paradigm. Proc Natl Acad Sci USA 87: 256-259.

Pardo JV, Pardo PJ, Janer KW, Raichle ME (1990b). The anterior cingulate cortex mediates processing selection in the Stroop attentional conflict paradigm. Proc Natl Acad Sci USA 87: 256-259.

Pomerleau CS, Teuscher F, Goeters S, Pomerleau OF (1994). Effects of nicotine abstinence and menstrual phase on task performance. Addict Behav 19: 357-362.
Provost SC, Woodward R (1991). Effects of nicotine gum on repeated administration of the Stroop test. Psychopharmacology (Berlin) 104: 536-540.

Rose JE, Behm FM, Westman EC, Mathew RJ, London ED, Hawk TC et al (2003). PET studies of the influences of nicotine on neural systems i cigarette smokers. Am J Psychiatry 160: 323-333.

Rusted JM, Caulfield D, King L, Goode A (2000). Moving out of the laboratory: does nicotine improve everyday attention? Behav Pharmacol 11: 621-629.

Sarter M, Hasselmo ME, Bruno JP, Givens B (2005). Unraveling the attentional functions of cortical cholinergic inputs: interactions between signal-driven and cognitive modulation of signal detection. Brain Res Brain Res Rev 48: 98-111.

Schuh KJ, Stitzer ML (1995). Desire to smoke during spaced smoking intervals. Psychopharmacology (Berlin) 120: 289-295.

Serences JT, Schwarzbach J, Courtney SM, Golay X, Yantis S (2004). Control of object-based attention in human cortex. Cereb Cortex 14: 1346-1357.

Stroop JR (1935). Studies of interference in serial verbal reactions. J Exp Psychol 18: 643-662.

Taylor SF, Kornblum S, Lauber EJ, Minoshima S, Koeppe RA (1997). Isolation of specific interference processing in the Stroop task: PET activation studies. Neuroimage 6: 81-92.

Thiel CM, Zilles K, Fink GR (2005). Nicotine modulates reorienting of visuospatial attention and neural activity in human parietal cortex. Neuropsychopharmacology 30: 810-820.

Thompson KG, Bichot NP (2005). A visual salience map in the primate frontal eye field. Prog Brain Res 147: 251-262.

Ward MF, Wender PH, Reimherr FW (1993). The Wender Utah Rating Scale: an aid in the retrospective diagnosis of childhood attention deficit hyperactivity disorder. Am J Psychiatry 150: 885-890.

Zysset S, Muller K, Lohmann G, von Cramon DY (2001). Colorword matching stroop task: separating interference and response conflict. Neuroimage 13: 29-36. 